\title{
Building Vietnamese Language System for Children 5-7 Years of Age with Montessori Method
}

\author{
Tuyen Thanh Dinh \\ Faculty of Early Childhood Education \\ Hanoi National University of Education, Hanoi, Vietnam \\ E-mail: tuyendt@hnue.edu.vn
}

Lan Thi Hoang

Department of Science Technology and International Cooperation

National College of Education, Hanoi, Vietnam

E-mail: hoanglansphn@gmail.com

Received: Oct. 5, $2019 \quad$ Accepted: Oct. 21, $2019 \quad$ Published: November 1, 2019

doi:10.5296/jse.v9i4.15579ＵRL: https://doi.org/10.5296/jse.v9i4.15579

\begin{abstract}
Language is a very socially important and basic structure of thought. It allows the child to integrate into society and dealing with abstract concepts. The principle of language education is that Montessori language is attached to human life; language is a form of sound or image that represents human perception of objective or subjective life. Thus, Maria's principle of language development is attached to things, from abstract objects to linguistic sounds, and from linguistic sounds to symbolic characters. This article systematizes Maria Montessori's core views on children's language acquisition as well as the principles affecting this process. Subsequently, it analyzes the development principles of the Montessori method as a basis for lesson and teaching tools development for Vietnamese language education.
\end{abstract}

Keywords: language, language acquisition, sensitive period, absorbent mind, teaching tools, language lessons 


\section{Introduction}

Language development is an important aspect of early childhood development in the first six years of life. Language contributes crucially to integrating the child into the community and becoming a member of society. Many researchers have spent considerable time and effort observing and finding ways to support the language development of children of this age, including Maria Montessori (Whitebread, 2012). Montessori not only expresses her theoretical views but more importantly, she and her collaborators have created and developed a systematic, scientific lessons and visual teaching tools to help children exploit the most of their "golden time" for language development in general and literacy in particular (Coombes, 2008; Gaunt, 2008). Understanding Maria Montessori's views will help us to make appropriate application in the context of Vietnamese language development at preschool age.

This paper analyzes development principles of the Montessori method as a basis for the development of lessons and teaching materials for Vietnamese language education.

\section{Language and the Absorbent Mind}

Maria Montessori observes that the minds of children are like a "sponge". But unlike a sponge that has dried up over time, the child's mind is always absorbing what he or she is exposed to, which she refers to as "absorbent mind". The absorbent mind of children may perceive everything from the environment without filtering. In the first 6 years of life, the mind unconsciously absorbs all the things in a certain period. This stage is referred by Maria Montessori as the "sensitive periods". However, as the absorbent mind has its limits, she determines that education plays an important role in re-organizing the environment so that it is useful for each stage of the child's development (Association Montessori International of the United States, 1997; Maloney, 1997; Oswald \& Schulz-Benesch, 1997).

The associated literature points out that the acquisition and learning of a child's language is a very mysterious and puzzling task that we have not previously given it a proper attention (Oswald \& Schulz-Benesch, 1997). In this paper, we discuss 'development' rather than 'teaching', because language is not something that a mother can teach a child. Language is natural development; it is natural creativity. At the same time, language development follows some fixed rules. Regardless of the living place, the language spoken, either simple or complex, the stages of language development are basically the same. The process of language learning in children is not a conscious process. On contrary, it starts and completes in the unconscious state of the brain. A language may become a part of the child upon hearing it spoken. It is a transcendent mechanism of nature (Oswald \& Schulz-Benesch, 1997). While observing the development of a child, Maria Montessori realized that the child absorbed the whole environment without any effort and in a totally unconscious way. The mind of the child will remain unconsciously absorbent and unselective until he or she is 5-6 years old. The whole mind of the child is being formed. By living and without any effort or consciousness, the child absorbs all the small details in his environment. By that way, the child's thinking is gradually formed. Maria Montessori compared the child's absorbent mind to a camera and found out that the images that would be automatically recorded on films, whether of one person or 10 people, were recorded in a blink of eye. Shooting 1000 people 
made no difference to one person (Kahn, 1990).

\section{Linguistically "Sensitive Period"}

Absorbent mind reveals its power through sensitive periods. When a child becomes sensitive to something, it is as if a light coming from the child is shining on that without anything else, from which the child's world is created (Ross, 2012). Montessori observed several important developmental stages in the early stages of a child's life. In this critical period, the child builds his/her own mental world, and this development usually occurs at specific times. When entering a sensitive stage of a particular personal aspect, a child will have a great finite time to acquire a certain attribute; otherwise, it would be very wasteful if the child missed this opportunity. Sensitive period is like a bright light, allowing the child to become skillful in a certain activity without much effort. Montessori realizes that the child is forming all of himself/herself, mentally and physically through the absorbent mind throughout the sensitive period and exploit everything in this environment to achieve his/her purpose. Throughout her observations, Maria Montessori also recognizes the great importance of a well-prepared environment in which the child can build his or her inner world. Thus, she has attempted to build the "Children's House" - a special setting that gives children the freedom to move and absorb everything they see (Haines, Baker \& Kahn, 2000).

According to Maria Montessori, the period of linguistic sensitivity may begin as early as from birth, which could be depicted by the smile of the child. Language is considered the best effort of the child. In order to get a command of the language, children need a certain amount of time, which is the sensitive period for language from 0-6 years old. If the language concept is not captured during this period, the child will never be able to learn the language. When the sensitive period becomes clear, it is important not to miss learning opportunities. Since birth, the child constantly absorbs the surrounding sounds. In the beginning stages, when there is not thought in the child's mind, those sounds may cause confusion for the child. The child's mind is filled with sounds, which he or she listens to and absorbs. It is in the linguistic sensitive period where the child's internal absorbent mind helps him or her understand these noises. When the noise is heard, the mouth and tongue muscles begin to move under the mechanism of speech sound production. When the child tries to understand the sound of the language, the mouth muscles will be rearranged, helping the child emit a lot of babbling (Montessori, 1912).

In the early stages of life, relatives communicate with children not only in language but also in non-verbal gestures. The language sounds are fixed in the child's subconscious and displayed later. Mother's body language and responses to baby's cry may affect the child's language development in later stages. As a result, negative attitude of language and body can delay children's language development process. Since birth, the cry of children carries different messages to adults, such as "I am hungry / wet / cold / tired". At 6 months old, the child cries and babbles and begins to understand his babbling such as "ba ba", "ma ma" ... At around 1 year of age, the child began to possess the very first words. Children begin to recognize things and name everything. Through repetitive language, the child becomes his or her own teacher. At the end of the first year of life, the child realizes that language aims to convey 
communication meaning in human life. Children quickly recognize the process and meaning of language. At the end of the first year, the child goes from unconsciously language learning to learning with consciousness (Howard, 2012). In the Montessori classroom, Maria Montessori calls the stage when the child begins to consciously use the words as "the second linguistically sensitive period". Two years of age acts as a new boundary of human psychology. The age of two marks the start for a period of language organization. In this period, language continues to grow, but the development progress, rather than a kind of explosion as before, has adopted a new, natural way. We must pay attention to both directions of normal development that shares a close relationship: one is the unconscious activities in the process of language learning, and the other is the mechanism of consciousness behind it (Montessori, 1912).

\section{Skill-based and Integrated Language Development to Other Factors}

Montessori (1912) recognizes the importance of the prepared environment and the relationship with the intellectual permeability so in the Montessori classroom, there are four linguistic aspects involved: listening, speaking, reading and writing.

She created linguistics-related learning tools. She said that the best time to learn to write is from 3.5 to 4.5 years of age. The integration of language development activities (listening, speaking, reading, writing) in the areas of the Montessori method is illustrated as follows:

\subsection{The Indicators of Language Development Activity in the Practical Life Corner}

Activities in the practical life corner indirectly prepare children to learn to write. The activities to pour and move objects teach children how to hold pencils and prepare them to learn to write later. Practical life corner helps children flex small muscles, creating maturity in fine motor activities supporting writing practice in later stages.

Children also learn vocabulary through communication in preschool. Communication is the key to building a child's intelligence, which leads to perfection in the child's speech. Real life practice exercises are taught with refined, precise, concise, simple, easy-to-understand words. The instructor speaks clearly, slowly, and can demonstrate the activity in silence or while observing the child. (For example, on pouring seeds into the funnel, children have the opportunity to use the senses of sight and hearing). Intelligence, concentration, coordination and good motor skills are being developed. Children are "refining" their feelings and emotions. The child is developing a part of his perception of small things. All these skills are essential for learning to write as well as developing hearing and language development in children (Messum, 2007).

Montessori (1912) exercises and treatments are designed to modify spoken language; however, she asserted that her teaching system also covers this aspect - that is, children's hands make the direct preparation for writing. For verbal words, psychological - motional impulses have been connected with the ready-made motion direction leading to the later outbreak of the writing behavior.

\subsection{Integration of Language Development Activities to the Sensorial Corner}

Between the ages of 2.5 and 3 years, children begin to take interest in sensory materials. 
Indirectly, sensory activities relate to the development of writing skills and further to children's language skills. The shapes of the sandpaper letters and the feeling of sandpaper cultivate the child's perception of the shapes of the letters. In this activity, touching the sandpaper letter is of primary importance to support the child's learning. The learning of different sensory shapes and the recognition of these shapes help develop the child's ability to write, and continue to develop his reading skill. A child always seeks to express his/her thoughts and cultivates his or her sensitive stage. Sensational activities as well as language-related materials will develop and refine the child's speech, language, and reading. Repetition of Exercises and Three-Step Lessons reinforces the child's understanding of concepts of reasoning, writing, and reading. Up to three, four-year-old, the child has already possessed the flexibility in using his vocabulary. Children have made effort to use singular, unstructured words. It is a sudden change when a child begins to see the meaning of his or her words and begins to make the sentence structured. At age four, the child will relate his or her speech to the written language (Lněničková, 2015).

In the sensorial corner of the classroom, an example of materials used for training and accomplishing the sense of hearing is: Bell and Sound Box. Both of these were done in silence with different levels of sound volume.

Silence games help the child adjust his listening sensation. Thus, in this particular phase, through the intervention and control of the external stimuli of the child, we can promote the development of their senses. This principle is similar to teaching children to speak when their language is yet fully developed (Montessori, 2012).

Lessons learned in the classroom are mostly done in silence. This allows the child to control his thoughts and his concentration. Montessori (2012) points out that the language will gradually improve, the hearing will "catch" each voice to put together a better word, the psychological motional impulses will also adjust the sound emitted more appropriately.

\subsection{Language Corner}

Montessori (2012) also says writing involves many difficult and complex problems, and we can isolate these problems and gradually overcome them through various forms of exercise at different stages for different age groups. The two different training components are: 1) Drawing helps the hand gain the control of the writing tool; 2) Descriptive letters can establish visual and motional memory for the letter. Montessori invented materials such as metal frames and sandpaper. Metal frames help children develop their skills and knowledge of linear drawing and keep them within the boundaries of the metal frame. With a crayon the child chooses, the child will fill in the numbers the child has drawn. These exercises indirectly lead children to the visualization of letters and numbers. In addition, children learn to accomplish the fine control of the pen. The cards on which the single letters in the alphabet are attached to the sandpaper, and the larger cards with groups of the same alphabet, help to develop the reading and writing skills. They help to develop the child's pronunciation of letters and sounds. The reading and writing exercises begin with the vowels and then introduce some consonants, creating a sound when these letters are linked together. The child learns to combine sounds when the letters are tied together through repetition of sound during or after the lesson. The three-step lesson is a teaching technique in the Montessori method. Step 1: Helping the child 
form the connection between the senses and the names, with the clear statement "This is A". Step 2: Recognizing the corresponding names, with the question: Can I just touch / get A? Or "Where is A?". Step 3: Memorizing the names corresponding to the item / teaching, with the question:" What is this?".

Montessori (1912) witnessed a sensational boom with letters of a child at the San Lorenzo Childhood Home when she was given a piece of chalk. People asked the children to paint the chimney of the house on the sidewalk. After the child completed the task, Maria Montessori complimented him. He said excitedly "I write, I write", and began to write "mano" on the brick. Later, he wrote "camino" (chimney) and "tetto" (roof). "I write this, I know how to write," he exclaimed. This is the first time a child has handled any writing tool and the first time he or she has written.

In the classroom of Maria Montessori, children are encouraged to learn to color, draw and make the name tags for the child to copy. Writing on sand trays helps children experiment with different shapes, additional lines and curves. These shapes are the basis for the formation of letters and numbers.

The book corner in early childhood classes is essential to refining the child's reading skill and further language skills of pronunciation and grammar. Teachers also play an important role in reading to children. Linguistic expression and attitude of the teacher when reading will impress children. Children always have the tendency to copy, so negative attitudes and language may interfere with the child's progress in reading. Reading is a fun and exciting activity. Reading time should be encouraged, first the teacher starts the story with one sentence, and the child then continues the story with his own sentence. This can be a group activity where all children continue the story with their own sentences. These activities develop children's ability to create and use their own language.

\subsection{Integration of Language Development in Math Corner}

Mathematical exercises introduce to children new vocabulary. They are taught the concepts of numbers and the vocabulary associated with each number. For example, in the number sticks game, the child continues to develop language as well as perception and knowledge of numbers.

\subsection{Integration of Language Development in Culture, Geography and History Corner}

Cultural activities introduce new language items, such as words like 'land', 'water' and 'globe'. Different cultural activities introduce children to different languages in the world. Teachers can introduce such words through cooking lessons or similar activities involving different cultures.

Teachers need to ensure that the environment is well prepared to provide the child with the best chance to learn the language. Teachers should closely observe the child and introduce appropriate materials to the child so that the child becomes ready for each stage.

Thus, it can be seen that Montessori has seen the integrated principles in language development and this viewpoint can possible be implemented in Vietnamese preschool education today. 


\section{List of Vietnamese Lessons Using Montessori Methods}

\subsection{Characteristics of Vietnamese Language}

As the Montessori language lessons and teaching materials always guarantee the principle of teaching language from the principle of combination: object - sound - character, when teaching Vietnamese language with the method of Montessori, this rule must be observed. Accordingly, the application of Vietnamese research findings to the development of Montessori-oriented Vietnamese language lessons is compulsory. The essence of applying Montessori method to teaching Vietnamese is to teach the language (including reading and writing) according to the phonetic principle. Therefore, the pronunciation of letters is taught, rather than shape signs of letters such as "o" is round like a chicken egg, "ô" wears a hat, and "o" grows beard". Teaching the sound mean teaching starts from the auditory canal, while teaching the letter bases on the visual channel. These two channels do not contradict each other, but use different approaches to learning to read and write. Similarly, Vietnamese has 29 letters, but there are 53 sounds (22 initial consonants, 14 main vowels, 1 middle sound, 10 final consonants and 6 tones - the ultrasonic sound). There are various forms of writing (visual signs) associated with different spelling rules.

In order to develop the Montessori-oriented Vietnamese language lessons and teaching materials, it is extremely necessary to create the list of sounds and sand letters, therefore creating buckets of sounds and letter cards for combining rhymes and reading syllables/words. In order to solve this problem, we look into the formation of Vietnamese phonetics as below:

\begin{tabular}{|c|c|c|c|}
\hline \multicolumn{3}{|c|}{ Tones } \\
\hline \multirow{3}{*}{ Consonant } & \multicolumn{3}{|c|}{ Rhymes } \\
\cline { 2 - 4 } & $\begin{array}{c}\text { middle } \\
\text { sound }\end{array}$ & $\begin{array}{c}\text { Main } \\
\text { vowel }\end{array}$ & $\begin{array}{c}\text { Final } \\
\text { consonant }\end{array}$ \\
\hline
\end{tabular}

This is also the table that creates the phonetic transcription rule, then the syllable/word of Vietnamese language, which is the basis of learning to read as well as the spelling rules of this language.

On the other hand, Vietnamese is an isolating language. Its isolation is expressed in terms of phonetics, vocabulary, and grammar. Thus, Vietnamese language does not consist of morphological forms of words, just lexical categories. Given that Vietnamese syllables are closely structured, closed and mostly meaningful, Vietnamese words are mostly single and phonetically fixed words in different grammatical relations; Vietnamese utterances use function words to express grammatical meanings, the development of lessons and teaching tools need adjusting accordingly and is somewhat different from the Montessori teaching tools for English language.

\subsection{Principles of Building Vietnamese Language Lessons Based on Montessori Perspective}

Multi-sensory principle: Language is an abstract signal system, using sound or scripting images that represent objects and phenomena in the objective world as well as the emotional attitude of human. Therefore, it is important to ensure the cognitive rules in general and 
cognitive rules of preschool children in particular, from visual intuition to abstract thinking.

The multi-sensory principle can be understood that the reference object for the sound of language or script must be a true, vivid and sentient object with as many senses as possible.

The multi-sensory principle is also expressed through the fact that the symbols of sound or script have two sides: physical appearance and meaning. While the meaning can be visualized by referring to real things, the physical side of the signal must also be perceived by the senses in the fullest extent. For example, the sound of language needs to be fully realized by auditory channel, from intonation, rhythm, speed, voice intensity of the words of the sentence, the tone of the syllable and especially, at the most sophisticated level, are the phonemes from which to form the basis of phonological and phonological perception in children, as a prerequisite for children's later reading and writing process. In terms of letters, it may be possible for the child not only to sense with sight but also touch, by the movement of the minor muscles while the hands move around the sand letters.

In order to sense the sound of Vietnamese language, this lesson system must be developed based on phonetic characteristics and syllable structures of Vietnamese language.

Sequence principle: object - sound - symbol (character): This sequence principle reflects and effectively implements the multi-sensory principle. The whole set of exercises will follow the sequence from the overall Vietnamese spoken language system to the detailed parts of the Vietnamese language: speech - vocabulary, grammar, syllables, phonemes, etc. as well as language skills: listening, speaking, reading, writing.

Sequential principle also demonstrates the development from spoken to written language, from listening - speaking skills to early literacy in early childhood and early elementary school.

The focus integration principle: Language is a communication tool, thus language exists in every activity and field. Therefore, any area of Montessori can also integrate children's language competence development. However, the language corner still needs to exist independently with the focus of supporting children with literacy skills in the future. To write effectively, vocabulary and grammar are not sufficient as the foundation of literacy is phonetic acquisition and the ability to think in a logical way (linguistic coherence). Thus, the Montessori language corner has the presence of the sound - the sand letters, the sound buckets (the buckets of things containing the phoneme). Books and stories also appears in this corner to assist children in accessing publications, forming a lifelong rapport to books, developing reading culture and develop linguistic coherence.

\subsection{List of Vietnamese Language Lessons}

Based on the abovementioned principles, the research briefly presents list of Vietnamese language lessons as below:

\begin{tabular}{|c|l|}
\hline A & SPOKEN LANGUAGE - for 2-6 years of age \\
\hline I. & ENRICHING VOCABULARY \\
\hline 1. & Etiquette \\
\hline 2. & Weekly sing-along songs (accompanied with CDs with illustrations and flash cards) \\
\hline
\end{tabular}




\begin{tabular}{|c|c|}
\hline 3. & Poem cards: small poems to cite / Singing rhymes \\
\hline 4. & Rhythm cards / Tongue-twisters / word connecting game \\
\hline 5. & Direction game: Objects in the environment \\
\hline 6. & Sensory vocabulary: attributes \\
\hline 7 & Categorized pictures and cards without label \\
\hline II. & EXPERIENCING SPOKEN LANGUAGE \\
\hline 1. & Spontaneous conversation in circle and in class \\
\hline 2. & Daily interaction with pictures/objects: Practice \\
\hline III. & PLAYING WITH SOUNDS -Corresponding signs \\
\hline 1. & Syllable game \\
\hline 1.1. & Clapping along the syllable \\
\hline 1.2 . & Finding number of buttons equal to the syllable number \\
\hline 1.3 . & How many syllables are there in your name? \\
\hline 2. & Rhyme game \\
\hline 2.1. & Reading traditional poems with rhyme \\
\hline 2.2 . & Reversed saying \\
\hline 2.3 . & Reduplication with similar rhymes \\
\hline 2.4. & Reduplication with the same rhymes \\
\hline 2.5 . & Odd one out: finding the word with different rhymes \\
\hline 3. & Playing with phonemes: Sounds and sand letters ( 2.5 years of age) \\
\hline \multirow[b]{2}{*}{3.1 . } & Monophthongs - corresponding Vietnamese letters \\
\hline & $\begin{array}{l}\text { Introduction to monophthongs } \\
\text { Hopping to monophthongs } \\
\text { Memory game } \\
\text { Pronouncing the sound and drawing along the letters (3-6 letters). } \\
\text { Finding and selecting the sand letter }\end{array}$ \\
\hline \multirow[b]{2}{*}{3.2 . } & Diphthongs (sounds from two letters combined) - combination of Vietnamese letters \\
\hline & $\begin{array}{l}\text { Introduction to diphthongs } \\
\text { Hopping to diphthongs } \\
\text { Memory game } \\
\text { Pronouncing the sound and drawing along the letters (3-6 letters). } \\
\text { Finding and selecting the sand letters }\end{array}$ \\
\hline \multirow[b]{2}{*}{3.3 . } & Tones \\
\hline & $\begin{array}{l}\text { Introduction to tones (with sand cards) } \\
\text { The roll of tones } \\
\text { Traditional game: Kim kỉm kìm kim... } \\
\text { Reduplication with similar tone }\end{array}$ \\
\hline \multirow[t]{3}{*}{4.} & Sand letters and bucket of sounds \\
\hline & monophthongs bucket \\
\hline & Diphthong bucket \\
\hline
\end{tabular}




\begin{tabular}{|c|c|}
\hline & Tones bucket \\
\hline B. & WRITING - 2,5-6 years of age (using the draft alphabet) \\
\hline 1. & $\begin{array}{l}\text { Sand tray } \\
\text { Drawing the letters in the air }\end{array}$ \\
\hline 2. & Sanding the letters \\
\hline 3. & Hopping on a letter \\
\hline 4. & Metal frame: straight and curved lines \\
\hline 5. & Drawing the alphabet \\
\hline 6. & Capital letters \\
\hline 7. & Chalk board to write \\
\hline 8. & Drawing letters according to objects - letter cards \\
\hline 9. & Drawing on flashcards of objects and letters \\
\hline 10. & Coloring names \\
\hline 11. & Sentence cards with illustrations \\
\hline 11.1. & Coloring the sentences and drawing the illustrations \\
\hline 11.2. & Making sentences and illustrations based on the provided example \\
\hline 12. & Writing a diary \\
\hline C. & READING - 3,5-6 years of age \\
\hline I. & READING LETTERS \\
\hline 1. & Introduction to separated and portable Vietnamese letter box \\
\hline 2. & Lower case letters \\
\hline 3. & Introduction: matching capital letters with lower case letters \\
\hline 4. & Interacting with lower case letter box \\
\hline 5. & Creating words on syllable/word (single word) mat with object drawers - word cards \\
\hline 6. & Practice reading letters \\
\hline II. & READING RHYTHMS \\
\hline 1. & Reading rhythms without middle sounds (simple rhythm) \\
\hline 2. & Reading rhythms with middle sounds (complicated rhythms) \\
\hline 3. & Game: finding the words with same rhythms (playing with word cards - illustrations) \\
\hline III. & READING SYLLABLES / WORDS \\
\hline 1. & Pronouncing simple syllables (without middle sound) \\
\hline 2. & Pronouncing complicated syllables (with middle sound) \\
\hline 3. & Singular word tree \\
\hline 4. & Syllable/Word Snake game \\
\hline IV. & READING SENTENCES \\
\hline 1. & Cards for commands \\
\hline 2. & Cards with illustrations \\
\hline
\end{tabular}




\begin{tabular}{|c|l|}
\hline 2.1 & Making sentences on Mat with lower case letter box \\
\hline 2.2 & Reading sentences \\
\hline 3. & First reading booklets \\
\hline
\end{tabular}

\section{Conclusion}

Language is human's fundamental means of communication and basic structure of thought. It allows children to integrate into the society and deal with abstract concepts. The child's absorbent mind is "instrumental" in learning language. If a child misses the sensitive period, his "window of opportunity" in learning languages, the opportunity will be gone forever. Whereas in case of English language, a set of lessons has been set up in terms of spoken and written language, Vietnamese language does not have any system of lessons that is developed according to the symbolic principles of object - sound - character. Therefore, the research focuses on building a systematic lesson for teaching Vietnamese language under the approach of Montessori method to help children develop language in their absorbent and sensitive stage.

\section{References}

Association Montessori International of the United States. (1997). The Relevance of Montessori Today Meeting Human Needs: Principles to Practice. Rochester, NY: Association Montessori International of the United States.

Coombes, S. (2008). Factors Which May Improve Standards of Speech and Language in the First Year of Key Stage 1. Unpublished Doctoral Dissertation, University of Brighton.

Gaunt, J. (2008). Developing Good Practice in the Provision of Outdoor Education in the Early Years. Unpublished Doctoral Dissertation, Nottingham Trent University.

Giau, T. V. (1979). Vietnamese worker class. Hanoi: Truth Publishing House.

Haines, A., Baker, K., \& Kahn, D. (2000). Optimal Developmental Outcomes: The Social, Moral, Cognitive, and Emotional Dimensions of a Montessori Education. Retrieved from http://www.ccma.ca/files/Outcomes_Kahn,_Baker_etc..pdf

Howard, L. (2012). The Context of Communication: Factors Affecting Early Language, Interaction and Socioemotional Development.Unpublished Doctoral Dissertation, Northumbria University.

Kahn, D. (1990). Implementing Montessori Education in the Public Sector. Cleveland Heights, OH: North American Montessori Teachers Association.

Khang, T. N., Trung, T. B., Hien, N. X. (1979). Rubber trees. Hanoi: Publishing House of Science and Technology.

Lněničková, I. (2015). Montessori Language Teaching: Materials Analysis and Evaluation. Brno: Masaryk University.

Maloney, C. (1997). Ritual and Pedagogy: Teachers' Use of Ritual in Preprimary Classroom Settings. Unpublished Doctoral Dissertation, Edith Cowan University. 


\section{Macrothink}

Journal of Studies in Education

ISSN 2162-6952 2019, Vol. 9, No. 4

Messum, P. R. (2007). The Role of Imitation in Learning to Pronounce. Unpublished Doctoral Dissertation, University College London.

Montessori, M. (1912). The Montessori Method: Scientific Pedagogy as Applied to Child Education in "The Children's House" with Additions and Revisions by the Author. New York: Frederic A. Stokes Company. https://doi.org/10.1037/13054-000

Oswald, P., \& Schulz-Benesch, G. (1997). Basic Ideas of Montessori's Educational Theory: Extracts from Maria Montessori's Writings and Teachings (The Clio Montessori Series). Santa Barbara, CA: ABC-CLIO.

Ross, S. (2012). The Montessori method: The development of a healthy pattern of desire in early childhood. Contagion: Journal of Violence, Mimesis, and Culture, 19, 87-122. https://doi.org/10.1353/ctn.2012.0004

Whitebread, D. (2012). The Importance of Play. Cambridge: University of Cambridge. 